\title{
UCRL-TR-218350
}

LAWRENCE LIVERMORE N A TIO N A L LABORATORY

Annual Report Electrochemical Machining of Access Holes

J. F. Cooper, M. Evans, R. Whipple

January 24, 2006 
This document was prepared as an account of work sponsored by an agency of the United States Government. Neither the United States Government nor the University of California nor any of their employees, makes any warranty, express or implied, or assumes any legal liability or responsibility for the accuracy, completeness, or usefulness of any information, apparatus, product, or process disclosed, or represents that its use would not infringe privately owned rights. Reference herein to any specific commercial product, process, or service by trade name, trademark, manufacturer, or otherwise, does not necessarily constitute or imply its endorsement, recommendation, or favoring by the United States Government or the University of California. The views and opinions of authors expressed herein do not necessarily state or reflect those of the United States Government or the University of California, and shall not be used for advertising or product endorsement purposes.

This work was performed under the auspices of the U.S. Department of Energy by University of California, Lawrence Livermore National Laboratory under Contract W-7405-Eng-48. 


\title{
Annual Report
}

\section{Electrochemical Machining of Access Holes}

\author{
John F. Cooper, Mark Evans and Richard Whipple \\ Chemistry and Materials Science Department
}

\begin{abstract}
$\underline{\text { Abstract }}$
We report the advances made in electrochemical machining of access holes through sheet metal during FY2005. The cutting tool underwent a major engineering re-design to accommodate an oblong cut with parallel sides (1.5" spacing) on a surface of arbitrary curvature. The solid cathode was replaced by an array of separately movable steel pins, allowing the tool to conform to the surface shape of the work piece prior to beginning cutting. Preliminary cuts through a hardened steel drum $(0.04$ inch thickness $)$ were successfully completed at a low current (50A) but the current efficiency of the cutting process was poor $(<30 \%)$. Efficiency was improved to $75 \%$ and the cutting time reduced to 8 minutes in heated electrolyte at $100 \mathrm{~A}$ and $4.5 \mathrm{~V}$. This work led to improvements in process simplicity and ease of operation: (1) continuous movement of the cathode towards the work piece was eliminated in favor of a fixed cathode; (2) the surfaces of the cutting pins do not require insulation; (3) a spider support for the tool provides for rapid positioning of the cutting tool; (4) negative electrolyte pressure minimized leakage into the drum following breakthrough. We found no reactivity of various HE's with alternative candidate ECM electrolytes.
\end{abstract}

\section{Introduction and Summary}

This year, a major engineering redesign effort lead to an improved cathode of oblong shape: two parallel sides spaced at $3.6 \mathrm{~cm}$ (1.4”), with semi-circular ends, and an overall length of 8 ". In addition to shape change, the advanced cutting process must meet the following specifications:

1. The cutting tool must conform and allow penetration of a surface of arbitrary curvature, including curvature in two dimensions of nonsymmetrical shape.

2. The electrolyte must be kept at negative pressure to atmosphere and thereby prevent or minimize leakage into the drum upon breakthrough.

3. The cutting procedure must be free of vibrations, high temperatures, sparks and acoustic signals.

4. The system must be portable with a setup time of 10 minutes, with penetration time of less than 15 minutes for a $2 \mathrm{~mm}$ thick work piece.

Using a heated electrolyte, we cut through a $1 \mathrm{~mm}$ thick drum of hardened steel in 8 minutes at a current of $100 \mathrm{~A}$ and a voltage of 4.6-5 V. The electrolyte was held at a negative pressure to atmosphere. The cut was made on a cylindrical surface between 
protruding ribs. A movable pin cathode was used to conform to the shape of the drum. The electrolyte was preheated to $43{ }^{\circ} \mathrm{C}$ before the cut.

The cutting tool is shown in Figure 1 (left) together with a shroud made of flexible polyurethane rubber which is affixed to the surface of the work piece using contact cement. Figure 1 (right) shows the assembly of independently movable pins held in contact with the cathode by a compression band of fiber reinforced Teflon. The pins are first brought in contact with the curved surface of the work piece, and then backed off with wing nuts to a fixed distance to allow electrolyte flow between the ends of the pins and the work piece.

Figure 2 shows the assembled system, with thermally insulated storage tank and work piece, found helpful in maintaining the final operating temperature of $43{ }^{\circ} \mathrm{C}$.

Figure 3 shows details of the attachment of cutting tool to drum and of the "spider" that holds the cutting tool to the drum through three legs attached to articulated joints cemented to the drum with fast set epoxy.

We selected the battery and overall controlling strategy for the system. The battery pack consists of two Optima 720 CCA Dual Post wound lead/acid gel batteries each with specifications 720 A peak current and $40 \mathrm{AH}$ (required: $100 \mathrm{~A}$ and $16 \mathrm{AH}$ ). The controller is a step-up/step-down DC/DC converter to yield the required voltage and current (100 A @ 4-6 V). A 3 V and 12 V lower and upper cutoff switches will be provided. Pumps will be run off a conventional $12 \mathrm{~V}$ DC to $110 \mathrm{~V}$ AC inverter using battery power.

The mid-project change in shape of the cutter (from circular to oblong slot) left insufficient time to address components in the balance of the system: plumbing, filtering, alternative electrolytes, controls and inverters, and circuitry for pressure-triggered shutoff of system. These are straight forward engineering tasks that can quickly be resolved.

In parallel with development and testing, we completed testing of 6 common HE chemicals in milligram quantities, each with three different electrolytes (chlorate, chloride, and nitrate). This confirmed a lack of reactivity in spot tests of all combinations. 

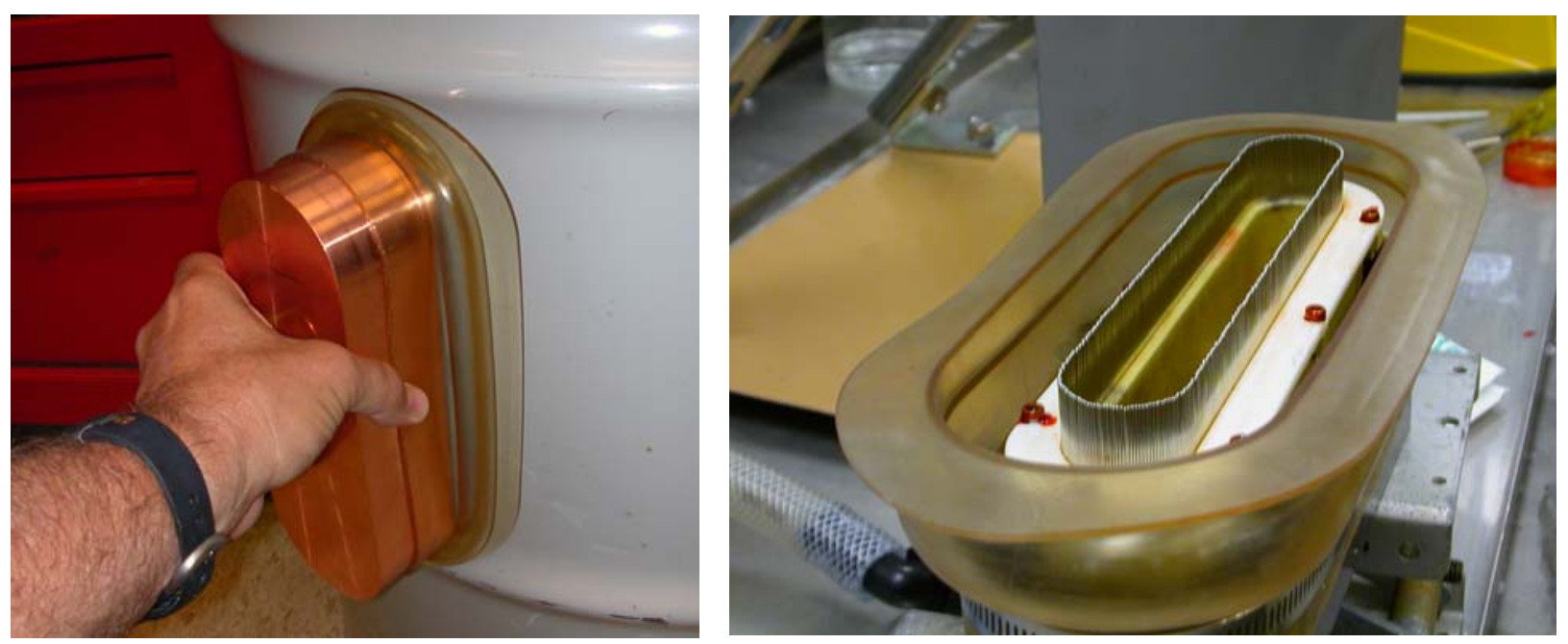

Figure 1. Shown (left) is the cutting tool (with polystyrene shroud but without connecting tubing), and (right) showing assembly of 532 steel pins, each of diameter 0.75 $\mathrm{mm}(0.032$ ") and protruding about $1.25 \mathrm{~cm}$ from plastic compression holder.

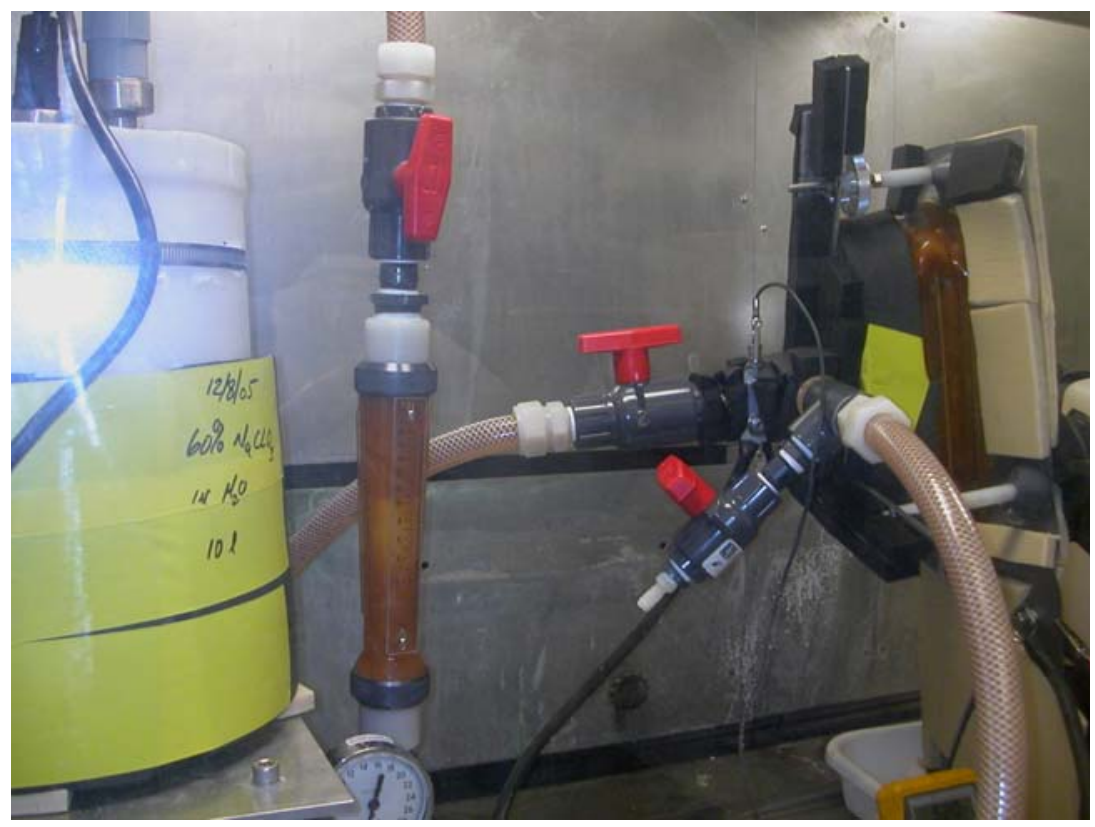

Figure 2. Experimental setup of 12/08/05, showing assembled cutting tool and spider affixed to drum. The relative orientation of cutter and surface are set and readjusted using three threaded nuts on the legs. Insulation maintains temperature of the electrolyte. 


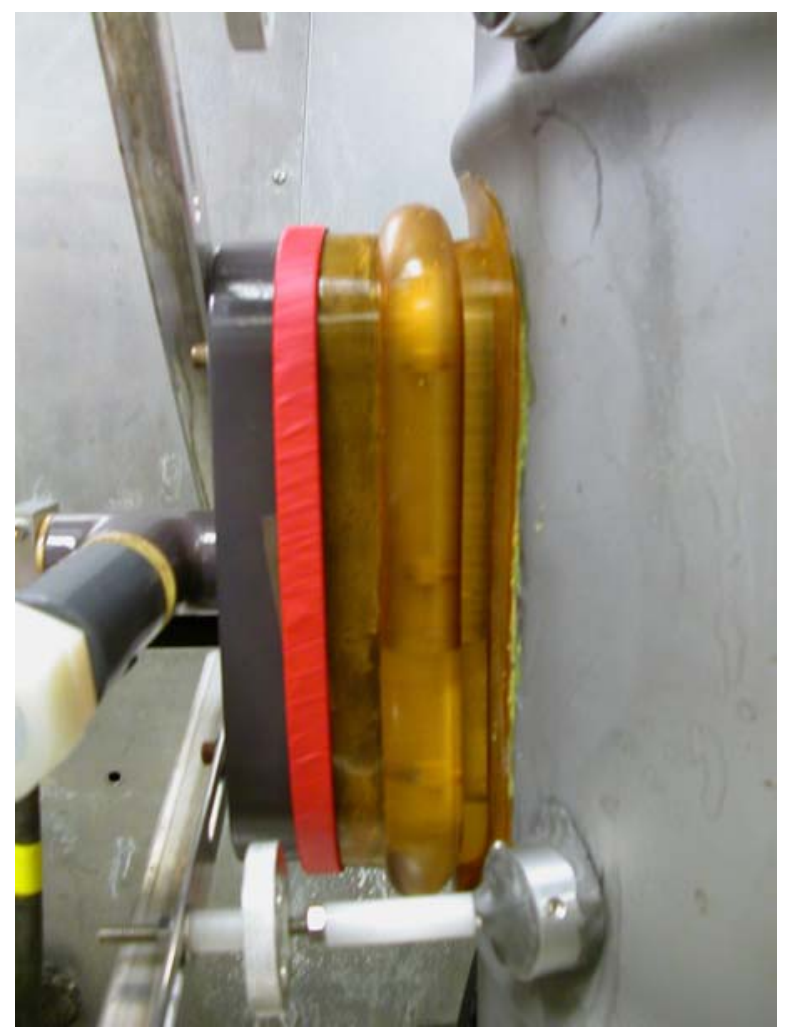

Figure 3. Detail of the anchors and feet. The anchors are cemented to the surface of the drum with fast setting Epoxy paste. Thereafter the feet are inserted and held in place with set screws. A red pipe clamp holds the polystyrene shroud to the cutting tool.

\section{Test results from trial cut of curved drum surface}

First Test Summary (October 28, 2005). An initial test was conducted on a segment of a waste drum constructed of 1080 steel, with a wall thickness of $1 \mathrm{~mm}(0.041$ in). The drum was made of 1080 cold rolled steel drum with composition, $0.1 \% \mathrm{C}, 0.06 \%$ $\mathrm{Mg}, 0.03 \% \mathrm{P}$, and $0.03 \% \mathrm{~S}$. Its thickness was measured at $1 \mathrm{~mm}(0.04 ")$. The inner and outer surfaces of the drum were coated with a polymeric layer; only the outer surface was removed with paint remover.

The electrolyte was $600 \mathrm{~g} \mathrm{NaClO} 3$ per liter solution (density $1.365 \mathrm{~g}$ ) at room temperature $\left(22^{\circ} \mathrm{C}\right)$ which rose during the experiment to $33{ }^{\circ} \mathrm{C}$. The cut was made at a low current of $50 \mathrm{~A}$, with the tool set at a fixed distance of $0.5 \mathrm{~mm}(0.020 \mathrm{in})$ from the work piece. The voltage applied to the cell to maintain this current was in the range of 4.5-5.5 V. The cut was completed in less than 1 hour and the efficiency was exceedingly poor. Less than $30 \%$ of the current was used to electrochemically dissolve the metal, assuming a valence of 3 equivalents per more.

The cut was clean and conformed to the curved surface of the drum. After the experiment, the oval shaped segment of drum remained fixed to the drum by a thin membrane of the internal polymer epoxy paint). The cut was incomplete in segments where a thin membrane of metal remained between segments where the metal had been completely removed (Figure 4). The oblong section was readily removed with a curved 
knife, and taped in place as shown in Figure 5 show exterior and interior surfaces of the drum.

Table 1 reproduces the data taken during the run. The low voltages $(4.5-5.0 \mathrm{~V})$ and currents $(50 \mathrm{~A})$ represent the lower edge of the electrochemical machining functionality, where a considerable amount of current is used to decompose water rather than to dissolve metal. A polarization curve was taken at the end of the experiment (Figure 6) showing linear increase of voltage with current. The flow rate was sufficient to carry away solid and gaseous reaction products yet maintain a pressure of between atmospheric and -2 psi. The voltage required for spark discharges (above 15-20 V) was not encountered.

The low efficiency and hence slow cut was attributed to the low current applied (50 A rather than the design current of $100 \mathrm{~A}$ ) and the low temperature of the electrolyte. While electrochemical machining did take place, the poor efficiency mandated improved operating conditions: increased current to $100 \mathrm{~A}$, elevated temperature $>40{ }^{\circ} \mathrm{C}$, and reduction of tool-to-work piece distance to $0.25 \mathrm{~mm}(0.010$ ") to improve efficiency and reduce the cutting time. These measures increased efficiency in the tests conducted in the previous work session.

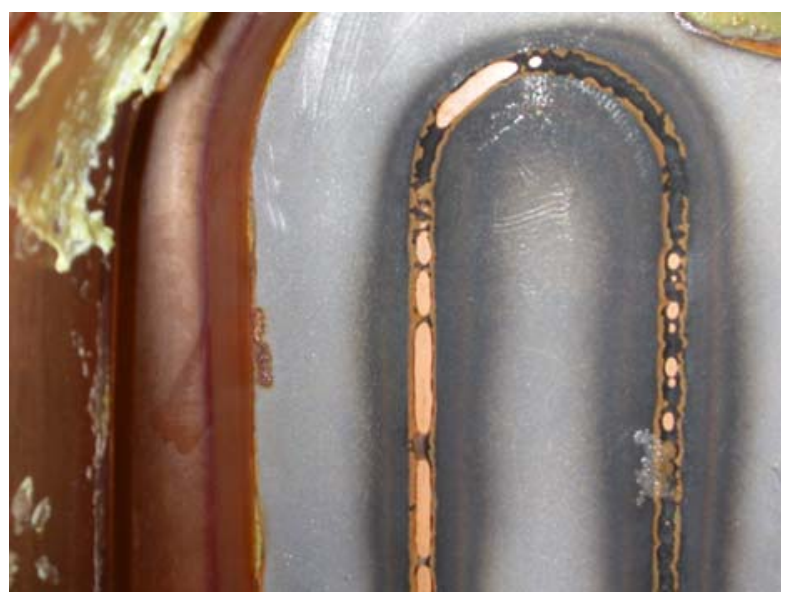

Figure 4. Detail of the cut piece before removal using knife, showing a series of breakthrough segments separated by incompletely removed but very thin segments. The incompletely removed segments were removed with a curved knife. 

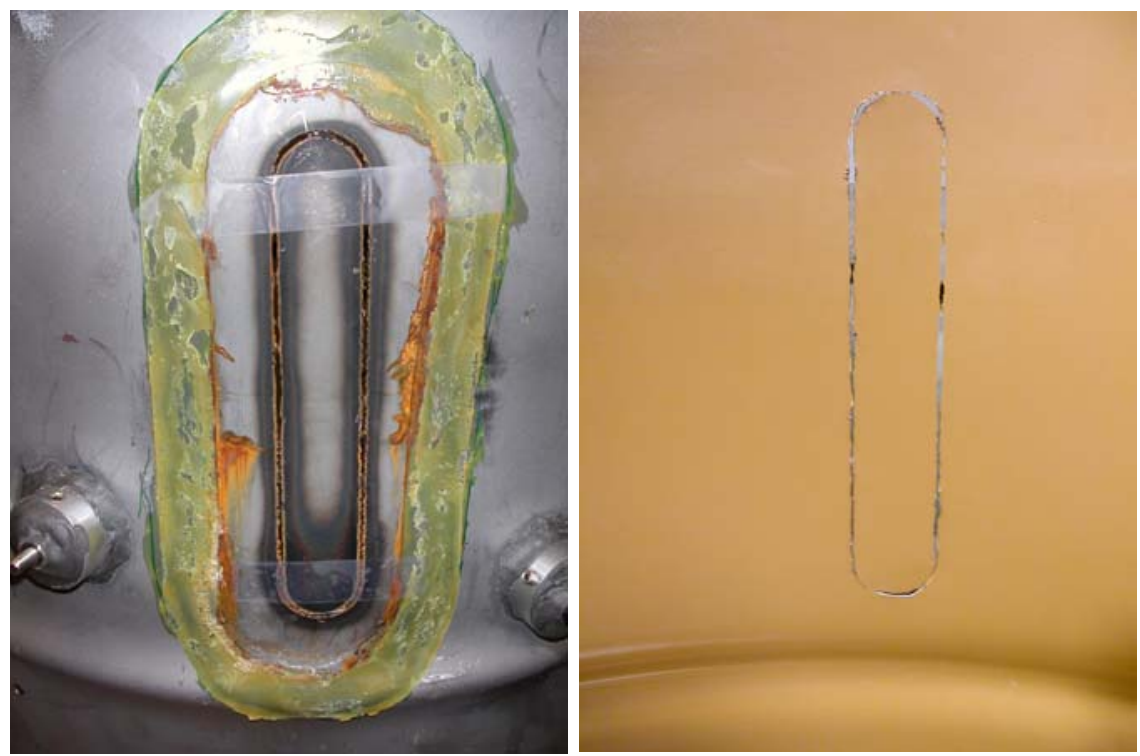

Figure 5. Completed cut shown (left) from exterior of drum and (right) from interior of drum. The cut piece was taped in place after removal. 
Table 1. Data from trial cut with stationary cathode. Anode/cathode initial separation $0.05 \mathrm{~cm} ; \mathrm{T}=23-33{ }^{\circ} \mathrm{C}$; electrolyte $\mathrm{NaClO}_{3}$, density $1.35 \mathrm{~g} / \mathrm{ml}$.

\begin{tabular}{|c|c|c|c|c|c|c|c|c|c|}
\hline Time (s) & Sum time (s) & Sum time (min) & Flow (g/min) & $I(A)$ & Ecell (V) & $\Delta P(p s i)$ & Charge $(\mathrm{AH})$ & Mass, $\mathrm{g}$ & Comments \\
\hline 60 & 60 & 1 & 8 & 50 & 5.3 & -4 & 0.8 & 0.6 & \\
\hline 60 & 120 & 2 & 8 & 50 & 5.3 & & 1.7 & 1.2 & \\
\hline 60 & 180 & 3 & 8 & 50 & 4.92 & & 2.5 & 1.7 & \\
\hline 30 & 210 & 3.5 & 10 & 50 & 0.33 & & 2.9 & 2.0 & short out \\
\hline 60 & 270 & 4.5 & 8 & 50 & 4.92 & & 3.8 & 2.6 & \\
\hline 60 & 330 & 5.5 & 8 & 50 & & & 4.6 & 3.2 & \\
\hline 120 & 450 & 7.5 & 9 & 50 & 4.87 & & 6.3 & 4.3 & \\
\hline 180 & 630 & 10.5 & 10 & 50 & 4.73 & & 8.8 & 6.1 & \\
\hline 240 & 870 & 14.5 & 9.2 & 50 & 4.7 & -0.5 & 12.1 & 8.4 & \\
\hline 300 & 1170 & 19.5 & 9 & 50 & 4.87 & -0.5 & 16.3 & 11.3 & \\
\hline 300 & 1470 & 24.5 & 9 & 50 & 4.89 & -0.5 & 20.4 & 14.2 & \\
\hline 300 & 1770 & 29.5 & 9 & 50 & 4.82 & -0.5 & 24.6 & 17.1 & \\
\hline 300 & 2070 & 34.5 & 9 & 50 & 4.87 & -0.5 & 28.8 & 20.0 & \\
\hline 300 & 2370 & 39.5 & 9 & 50 & 4.57 & -1.5 & 32.9 & 22.9 & Breakthrough \\
\hline 600 & 2970 & 49.5 & 8 & 50 & 4.55 & -2 & 41.3 & 28.6 & Breakthrough \\
\hline \multirow[t]{10}{*}{600} & 3570 & 59.5 & 9 & 50 & 4.76 & -2 & 49.6 & 34.4 & Breakthrough \\
\hline & & & & 30 & 4.07 & & & & Polarization \\
\hline & & & & 40 & 4.6 & & & & Polarization \\
\hline & & & & 50 & 4.66 & & & & Polarization \\
\hline & & & & 60 & 4.99 & & & & Polarization \\
\hline & & & & 70 & 5.36 & & & & Polarization \\
\hline & & & & 80 & 5.56 & & & & Polarization \\
\hline & & & & 90 & 6.1 & & & & Polarization \\
\hline & & & & 100 & 6.43 & & & & Polarization \\
\hline & & & & 50 & 4.9 & & & & Polarization \\
\hline
\end{tabular}

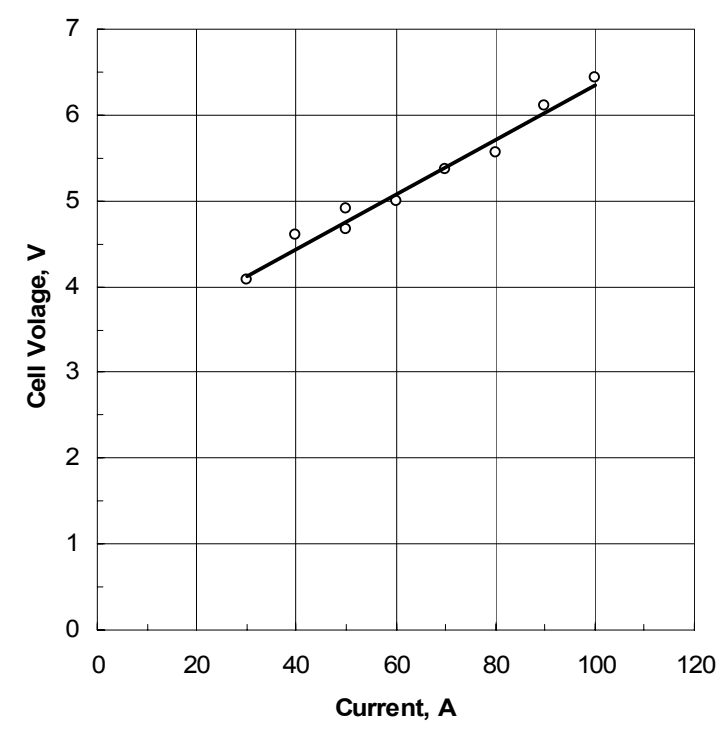

Figure 6. Polarization and end of run (following breakthrough). $\mathrm{T}=33^{\circ} \mathrm{C}$, pressure drop $=-13.7 \mathrm{kPa}(-2 \mathrm{psi})$; flow rate $=0.57 \mathrm{~L} / \mathrm{s}(9 \mathrm{gpm})$. 
Second Test Summary (12/08/05). In a second test, the electrolyte was preheated to $43{ }^{\circ} \mathrm{C}$ and the electrolyte tank and connecting plumbing were insulated to prevent heat loss. Based on the polarization curve linearity, we raised the voltage to allow a current of $100 \mathrm{~A}$. The high temperature allowed such high currents without appreciable increase in cell voltage (from about $4.7 \mathrm{~V}$ to $5.3 \mathrm{~V}$ ) - still in a regime compatible with storage battery power and well below the level of dielectric breakdown of the thin gas layers adjacent to the electrode surfaces.

Table 2 shows voltage increases for fixed electrolyte flow (8 gpm), current (100 A), with measured pressure drop of -1 psi relative to atmosphere. Breakdown was first observed at about 8 minutes, but the current was allowed to pass an additional 3 minutes with the electrolyte under negative pressure, with air being drawn into the electrolyte flow. There was some minimal amount of electrolyte leakage on the interior of the drum. The calculated amount of material removed from the drum (11.6 g) was 33\% more than estimates from the geometry of the cut, indicating an overall current efficiency of $75 \%$.

Table 2. Data from trial cut (12/08/05) with stationary cathode. Fixed cathode. Anode/cathode initial separation $0.05 \mathrm{~cm} ; \mathrm{T}=43{ }^{\circ} \mathrm{C}$; electrolyte $\mathrm{NaClO}_{3}$, density 1.35 $\mathrm{g} / \mathrm{ml}$. Calculation of mass removed assumes $100 \%$ efficiency for $\mathrm{n}=3$ equivalents $/ \mathrm{mole}$ Fe.

$\begin{array}{cccccccccc}\text { Time (s) } & \text { Sum time (s) } & \text { Sum time (min) } & \text { Flow }(\mathrm{g} / \mathrm{min}) & \mathrm{I}(\mathrm{A}) & \text { Ecell }(\mathrm{V}) & \Delta \mathrm{P}(\mathrm{psi}) & \text { Charge }(\mathrm{AH}) & \text { Mass, } \mathrm{g} & \text { Comments } \\ 120 & 120 & 2 & 8 & 100 & 4.33 & -1 & 3.3 & 2.3 & \\ 180 & 300 & 5 & 8 & 100 & 5.27 & & 8.3 & 5.8 & \\ 300 & 600 & 10 & 8 & 100 & 5.32 & & 16.7 & 11.6 & \text { breakthrough } \sim 8 \mathrm{~min}\end{array}$

The efficiency of the process was estimated as follows. Breakthrough occurred at approximately 8 minutes, after removal of approximately $9.26 \mathrm{~g}$ of steel or $13.3 \mathrm{Ah}$ of charge passed. This corresponds to a volume of $11.8 \mathrm{~cm}^{3}$ (for $00 \%$ efficiency and 3 equivalents of charge per mole of iron). The dimensions of the cut are roughly $35.3 \mathrm{~cm}$ circumference x $0.1 \mathrm{~cm}$ deep x $0.25 \mathrm{~cm}$ wide $(13.9$ " circumference x 0.04 " deep x 0.1 " wide), corresponding to a volume of $0.897 \mathrm{~cm}^{3}$ and a mass of $7.0 \mathrm{~g}$. Comparing the theoretical amount removed of $9.26 \mathrm{~g}$ with the estimate of the actual amount removed, 7 $\mathrm{g}$, indicates an efficiency of about $75 \%$.

The same calculation for trial run at $50 \mathrm{~A}$ and ambient temperature indicates very poor efficiency, less than 30\% efficiency. Clearly, the high temperature and current density resulted in a very favorable increase of cutting efficiency and corresponding reduction in cutting time.

The cut was incomplete, with a $4 \mathrm{~cm}$ segment of the circumference apparently not cut at all. We measured the resistance between the individual pins and the common cathode manifold at various points around the periphery of the cut. An unusually high resistance was found on points of the pin assembly corresponding to the uncut segments of the work piece, as shown in Figure 7. The high resistance was attributed to residues of lacquer that had been used in earlier experiments to shield the surfaces of the pins not directly opposite the work piece. This lacquer had been removed before the final experiment. 


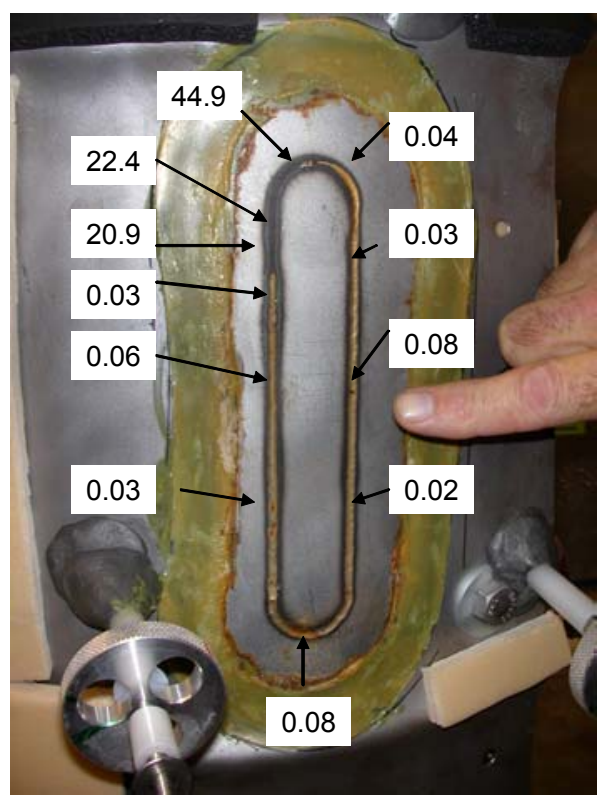

Figure 7. The work piece was not etched over a $4 \mathrm{~cm}$ segment. Resistances between the pins and the common cathode inlet manifold are superimposed on the image of the work piece. The uncut segment corresponded to an unusually high resistance.

\section{Reactivity of ECM Electrolytes and Various HE Materials}

(Rich Whipple, Forensics Science Center, and John F. Cooper, CMSD)

Samples of diverse HE materials were tested for reactivity with three candidate ECM electrolytes. The HE samples included RDX, HMX, PETN, TNT and CL2-0. The electrolytes tested included three commonly used electrolytes: water solutions of sodium chlorate, sodium chloride and sodium nitrate. The weighted samples (typically 9-10 mg) were placed in $4 \mathrm{ml}$ vials containing $1 \mathrm{ml}$ each of the solutions at room temperature. The solids were inspected within 1 hour of immersion, 24 hours after immersion and 124 hours after immersion. The results are given in Table 3. "No reaction" means no visible discoloration or tangible heating occurred.

These results are for initial survey purposes only. More detailed studies would be required to determine whether trace surface reactions could lead to sensitization of the explosives. It has been suggested to us that an acidic solution of sodium chlorate might show increased reactivity. (Our solutions were all at neutral $\mathrm{pH}$ ). 
Table 3. Observations of reactivity of diverse samples of HE with candidate ECM electrolytes solutions. $5.6 \mathrm{M} \mathrm{NaClO}_{3}$ (density $\left.=1.359 \mathrm{~g} / \mathrm{ml}\right) ; 5 \mathrm{M} \mathrm{NaCl}(29.2 \mathrm{~g} \mathrm{NaCl} / 100$ $\mathrm{ml}$ solution); $5 \mathrm{M} \mathrm{NaNO}_{3}\left(42 \mathrm{~g} \mathrm{NaNO}_{3} / 100 \mathrm{ml}\right.$ solution).

\begin{tabular}{|c|c|c|c|c|c|}
\hline $\begin{array}{l}\text { Sample/ } \\
\text { lot number }\end{array}$ & $\begin{array}{c}\text { Weight HE } \\
\text { (mg) }\end{array}$ & Solution & $<1 \mathrm{~h}$ & $24 \mathrm{~h}$ & $124 \mathrm{~h}$ \\
\hline \multirow{3}{*}{$\begin{array}{l}\text { RDX, } \\
\text { C-89 }\end{array}$} & 9 & $\mathrm{NaClO}_{3}$ & No reaction & No reaction & No reaction \\
\hline & 10 & $\mathrm{NaCl}$ & No reaction & No reaction & No reaction \\
\hline & 9 & $\mathrm{NaNO}_{3}$ & No reaction & No reaction & No reaction \\
\hline \multirow{3}{*}{$\begin{array}{c}\text { HMX, } \\
\text { B881 }\end{array}$} & 9 & $\mathrm{NaClO}_{3}$ & No reaction & No reaction & No reaction \\
\hline & 9 & $\mathrm{NaCl}$ & No reaction & No reaction & No reaction \\
\hline & 9 & $\mathrm{NaNO}_{3}$ & No reaction & No reaction & No reaction \\
\hline \multirow{3}{*}{$\begin{array}{c}\text { PETN, } \\
\text { B509 }\end{array}$} & 9 & $\mathrm{NaClO}_{3}$ & No reaction & No reaction & No reaction \\
\hline & 9 & $\mathrm{NaCl}$ & No reaction & No reaction & No reaction \\
\hline & 9 & $\mathrm{NaNO}_{3}$ & No reaction & No reaction & No reaction \\
\hline \multirow{3}{*}{$\begin{array}{l}\text { TNT, } \\
\text { B-569 }\end{array}$} & 9 & $\mathrm{NaClO}_{3}$ & No reaction & No reaction & No reaction \\
\hline & 10 & $\mathrm{NaCl}$ & No reaction & No reaction & No reaction \\
\hline & 9 & $\mathrm{NaNO}_{3}$ & No reaction & No reaction & No reaction \\
\hline \multirow{3}{*}{$\begin{array}{l}\text { CL20, } \\
\text { C-142 }\end{array}$} & 9 & $\mathrm{NaClO}_{3}$ & No reaction & No reaction & No reaction \\
\hline & 9 & $\mathrm{NaCl}$ & No reaction & No reaction & No reaction \\
\hline & 9 & $\mathrm{NaNO}_{3}$ & No reaction & No reaction & No reaction \\
\hline
\end{tabular}

\section{Conclusions}

The conclusions of this work are as follows:

1. The replacement of the rigid ring cathode with an array of 532 independently movable pins allows the cutting tool to conform to the surface of the work piece; the technique is similar to that of a common pin contour gage.

2. There does not appear to be any need to coat the parallel surfaces of the cathode to restrict current flow to the cathode directly opposite the work piece. The passivation of the work piece by the action of the oxidizing electrolyte is sufficient to channel the flow of current. This obviates a major difficulty encountered in the previous work period (FY2004)-i.e., the adherence of a polymer coating to the surface of the pins or cathode ring.

3. There does not appear to be any value of advancing of the cathode towards the work piece during the cut to maintain a constant separation. A fixed position of the cathode relative to the work piece (at a distance of 0.25 $\mathrm{mm}, 0.010$ ") is sufficient to allow the desired flow at a minimal pressure drop. It may still be desirable to periodically reposition the cathode once or twice during the cutting of a very thick work piece (say $2-5 \mathrm{~mm}$ ), but continuous movement does not appear necessary. 
4. Some elevation of the electrolyte temperature to about $40-45^{\circ} \mathrm{C}$ is necessary to increase conductivity, maintain a low cell voltage, and to reduce pressure drop for fluid flow through the inter-electrode gap. The amount of energy required from the batteries to accomplish this with use of resistive heaters is negligible compared with the electrochemical energy required for dissolving the metal.

5. The existing spider assembly for holding the cathode in place was found to be cumbersome and difficult to adjust, because the spider-to-leg joints showed too much flexibility. One improved design is given below.

\section{Recommendations}

The following recommendations are made for rapidly constructing an apparatus for field tests.

1. Configure the apparatus for use of unshielded, independently movable pins, elevated temperature $\left(40-45^{\circ} \mathrm{C}\right)$, currents between 100 and $200 \mathrm{~A}$, and voltages between 5 - and $10 \mathrm{~V}$. Flowing electrolyte will be used sodium chlorate at a density of $1.35 \mathrm{~g} / \mathrm{ml}$.

2. Upgrade the spider to a configuration such as shown in Figure 7. This features constraining the positioning legs by holding them within three steel tubes welded to the three-legged spider.

3. Maintain the transparent polystyrene shroud, but decrease the size to prevent gas entrapment in the shroud. Maintain the use of fast-setting epoxy to cement the spider and cathode assembly to the work piece through ball-and-socket joints to conform to the curvature of the surface.

4. Use two parallel lead acid batteries and appropriate DC/DC control and step down voltage to provide sufficient amperage at less than $10 \mathrm{~V}$. Use standard $110 \mathrm{~V} \mathrm{AC}$ hardware (pumps, controls, etc.) through 12V DC to $110 \mathrm{~V}$ AC low wattage inverters.

5. Use an inventory of 10-15 liters of electrolyte, unfiltered, and contained in an insulated tank, open to the top.

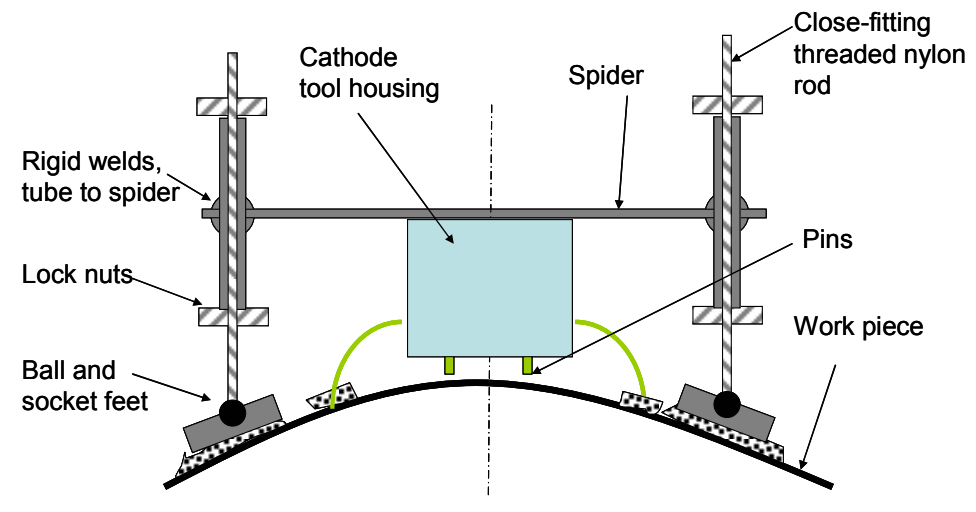

Figure 8. Improved spider design to hold cathode rigid relative to work piece.

\section{Acknowledgments}

This work was performed under the auspices of the U.S. Department of Energy by University of California Lawrence Livermore National Laboratory under contract No. W-7405-Eng48. 